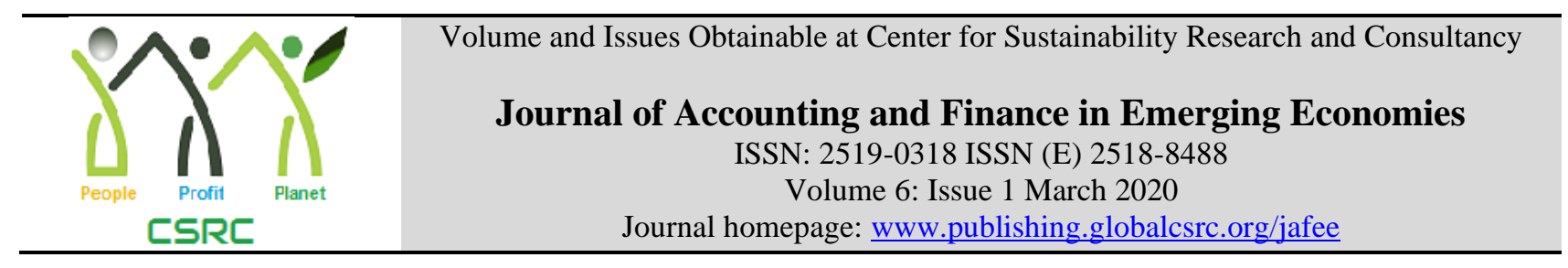

\title{
Hospital Service Quality and Patient Satisfaction: A Moderating Role of Trustworthiness
}

\author{
${ }^{1}$ Tariq Rafi, ${ }^{2}$ Muhammad Khalique, ${ }^{3}$ Sulaman Hafeez Siddiqui \\ ${ }^{1}$ Jinnah Post Graduate Medical Centre, Pakistan; rafi57@ hotmail.com \\ ${ }^{2}$ Assistant Professor,MUST Business School (MBS) Mirpur University of Science and Technology(MUST), \\ Mirpur Azad Jammu and Kashmir, Pakistan: drmkhalique@ gmail.com \\ ${ }^{3}$ Lecturer Department of Management Sciences, The Islamia University of Bahawalpur, Bahawalpur, 63100 \\ Pakistan: sulman.siddiqui@iub.edu.pk
}

\begin{tabular}{ll}
\hline \multicolumn{1}{c}{ ARTICLE DETAILS } & ABSTRACT \\
\hline $\begin{array}{l}\text { Hevistory } \\
\text { Available Online: } \text { March } 2020\end{array}$ & $\begin{array}{l}\text { The aim of the present study is to determine the effects of hospital service } \\
\text { qualities on patient satisfaction in the healthcare sector of Pakistan. By } \\
\text { using the non-probability sampling, 292 sample was gathered. Emotional } \\
\text { exhaustion, organizational citizenship behavior, hospital and nurses } \\
\text { facilities were used as predictors and trustworthiness was used as a } \\
\text { moderator. The results from structural equation modeling revealed that }\end{array}$ \\
$\begin{array}{l}\text { Kursing Service Quality, Hospital } \\
\text { Facilities Quality, Emotional }\end{array}$ & $\begin{array}{l}\text { hospital facilities quality and OCB have been found positively significant } \\
\text { while nursing service quality and emotional exhaustion have been found } \\
\text { Citizenship Behavior, Patient } \\
\text { insignificant in relation with patient satisfaction. Moreover, } \\
\text { trustworthiness does not moderates any relationship in the structural } \\
\text { model. The study concluded that the staff allocated is manifesting form of } \\
\text { behavioral citizenship structured by cultural decorum and locally } \\
\text { acceptable norms. Alongside citizenship, high quality miscellaneous } \\
\text { P36, I18, D23, D29 }\end{array}$ \\
supportive provisions comprising of sufficient backup equipment, medical \\
apparatus and tools as well as the regular maintenance of utilities stand as \\
considerable satisfaction determining aspects for patients. The cognitive \\
dimensions in the form of trust structuring attributes don't really add \\
much to the contributions of facilities and citizenship found in hospitals.
\end{tabular}

OPEN ACCESS

(C) 2020 The authors, under a Creative Commons Attribution-Non

Commercial 4.0

Corresponding author's email address: rafi57@ hotmail.com

Recommended citation: Rafi, T., Khalique,. \& Siddiqui, S. H., (2020). Hospital Service Quality and Patient Satisfaction: A Moderating Role of Trustworthiness. Journal of Accounting and Finance in Emerging Economies, 6 (1), 237-250

DOI: $10.26710 /$ jafee.v6i1.1081

\section{Introduction}

Since few decades, the improvement in the process of nursing and hospital services have become major concern in Pakistan. Patient satisfaction with healthcare services is an important performance measure for healthcare providers. The preference for the healthcare organization is revealed from the patient centeredness that is implementing particular policies for achieving this objective (Silva, Ferreira, \& 
Daniel, 2018). A more effective and efficient use of resources as well as better performance of healthcare organizations is ensured as there are social stimulations in order to enhance the well-being and health of individuals and economic objectives behind these policies (Oppel, Winter, \& Schreyögg, 2017; Tartaglione, Cavacece, Cassia, \& Russo, 2018). Patients' satisfaction with quality of care has been revealed as an important component that explains a competitive position and survival of the hospital (Coutinho \& da Costa Vieira, 2018).

It has been deemed that positive word of mouth is revealed from the satisfied patients that are usually returned due to their involvement in the hospitals. On the other hand, negative word-of-mouth, repeated investigations, and complaints, and second opinions are driven through the dissatisfaction. Thereby, a requirement for maintaining and expanding a patient base of hospital is due to high levels of patient satisfaction (Oppel et al., 2017).

Furthermore, past studies have shown that patient's satisfaction can be improved by nursing service quality (Coutinho \& da Costa Vieira, 2018). In this context, Lukman, Tiara, and Mei (2017b) proclaimed that nursing service quality that ensure hospitality, good quality healthcare attention and courtesy. Henceforth, nursing service quality and patient satisfaction have significantly positive relationship that was also profoundly supported by (Aslan \& Yildirim, 2017; Kaihatu \& Djati, 2016; Ríos-Risquez \& García-Izquierdo, 2016). In addition, nursing service quality was also considered an important factor, having positively significant impact, on patient satisfaction (Al-Hussami et al., 2017).

Moreover, numerous past researches have also shown that hospital facilities quality can help to improve patient satisfaction (Coutinho \& da Costa Vieira, 2018). In this regards, there were ample literature that postulated positively significant relationship between hospital facilities quality and patient satisfaction (Halim \& Sriwahyuni, 2017; Ziapour, Khatony, Jafari, \& Kianipour, 2016). Another recent study claimed that patient satisfaction can be improved by adequate quality of hospital facilities (Sahu, Abdullah, \& Masood, 2017). On the contrary, Patil and Shah (2018) found that quality of hospital facilities have none contribution to patient overall satisfaction with the hospital.

However, various studies in the past suggested that emotional exhaustion can decrease patient's satisfaction with the hospital and healthcare organizations (Ríos-Risquez \& García-Izquierdo, 2016). There are extant studies of the recent times that recognized consequences of hospital staffs' emotional exhaustion (Boamah, Read, \& Spence Laschinger, 2017; Boissy et al., 2016; Shanafelt et al., 2015). While some have identified that emotional exhaustion can leads to declining patient satisfaction (Dhaini et al., 2018; Edwards et al., 2018; B Hayes, Douglas, \& Bonner, 2015; Nelson et al., 2014; Pinchbeck, Weygandt, Gisondi, \& Lu, 2016).

While, it was also pronounced by the research that organizational citizenship behavior of the hospital staff and healthcare practitioners can considerably improve patient satisfaction (Oppel et al., 2017). Also, it has been manifested that organizational citizenship behavior helps to improve patient satisfaction (Kaihatu \& Djati, 2016), whereas another study supported the similar argument and postulating positively significant relationship between organization citizenship behavior and patient satisfaction (Mahooti et al., 2018). In addition, Aslan and Yildirim (2017) have shared the viewpoint that private hospitals have patientcenteredness at their forefront; eventually, the organizational citizenship behavior of the nurses contributes to patient satisfaction.

Additionally, healthcare practitioners' trustworthiness can help to improve patient satisfaction in the presence of various other factors (Van Den Assem \& Dulewicz, 2015), whereas Ferrand et al. (2016) attributed trustworthiness as an essential ingredient for patient satisfaction. Similarly, Van Den Assem and Dulewicz (2014) manifested that trustworthiness plays important role in improving patient satisfaction and it does have significant moderating role between the factors affecting patient satisfaction. 
Henceforth, on the guidelines of Creswell (2009) for purpose statement and based on aforementioned scholarly discussions, the purpose of this survey study is to determine the impact of nursing service quality, hospital facilities quality, emotional exhaustion and organizational citizenship behavior on patient satisfaction moderated by trustworthiness in the hospitals of Karachi, Pakistan.

\section{Literature Review}

\subsection{Nursing Service Quality and Patient Satisfaction}

It has been exhibited that each individual possess different personality characteristics, values, and resilience that influence their satisfaction with the service provided by the hospital in order to make the notion highly complex even though patients categorize great significance of the opportunities of a regimen for the ailment that afflicts them, factors that provide them emotional and physical comfort, and reduction of their suffering (Al-Hussami et al., 2017; Ferrand et al., 2016) (De Man et al., 2002; Kaihatu \& Djati, 2016). Moreover, Boamah et al. (2017) have revealed that assorted service quality determinants were significant for patient satisfaction, which include professional attitude of the physicians and nurses, attitude of respect, empathy and kindness, and technical competence of all the healthcare practitioners. In addition, Ríos-Risquez and García-Izquierdo (2016) have exhibited that the doctor's technical competence presumed by the patients by means of the minimization of their pain as well as to restore their health, which stresses upon significance for the service satisfaction Aljaberi et al. (2018) have further revealed that value of patients is explained by the doctor who provides regarding the treatment and the time spend in order to listen and to examine them. Hence, following hypothesis has been developed on the theoretical and empirical evidences.

H1: Nursing service quality has significant relationship with patient satisfaction.

\subsection{Hospital Facilities Quality and Patient Satisfaction}

There is a tendency among loyal patients who are contended with the services provided by a hospital. This allows them to praise and suggest the hospital for its better service in spite of being important for service consumption (Al-Hussami et al., 2017). Patients have extensive complexity in order to evaluate it in terms to the technical service quality as they do not possess enough technical knowledge for conjecturing whether the medical evaluation is brief and if the surgical method or treatment used was appropriate and accomplished the effective consequences (Aljaberi et al., 2018; De Man et al., 2002; Lukman et al., 2017b). on the other hand, this irrelevancy of the patients is not revealed from the impairment of making a brief assessment of the technical quality of the service (Kaihatu \& Djati, 2016; Nelson et al., 2014). In contrast, it is highly competent in order to reduce their recovery of better health and their suffering (Shah et al., 2018; Silva et al., 2018). Henceforth, the study has developed following hypothesis between hospital facilities quality and patient satisfaction.

$\mathrm{H} 2$ :Hospital facilities quality has significant relationship with patient satisfaction.

\subsection{Emotional Exhaustion And Patient Satisfaction}

Emotional exhaustion is defined as the degree to which employees feel emotionally drained and overwhelmed by their work. Employees face stress when they experience warnings that might come from actual resource loss, insufficient return of supplementary resources on investments of resources, and a risk of resource loss (Dhaini et al., 2018; Janssen et al., 2010). Feelings of emotional exhaustion are driven from the experienced stress when employees feel that their resources specifically might not be sufficient enough to acquire existing work demands after a great deal of resource investments in work (Bronwyn Hayes, Douglas, \& Bonner, 2014; Pinchbeck et al., 2016). Employees become motivated for examining the cause of their worn-out state and to explore approaches in which they can replenish or protect their depleting resources in terms of a current challenge (Janssen et al., 2010). Hence, the study has developed following hypothesis. 
H3:Emotional exhaustion has significant relationship with patient satisfaction.

\subsection{Relationship Between Organizational Citizenship Behavior and Patient Satisfaction}

Better survival consequences are presented among patients who were more satisfied as compared to the patients who were less satisfied (Ahmadzadeh Mashinchi, 2011). They characterized this aspect to psychological aspects that improvise immunity and provide patients more encouragement in order to appropriately follow the nutritional and medical treatment instructions (Kaihatu \& Djati, 2016). The integration of organizational citizenship behavior and consideration to the extent of satisfaction will be enabled for eradicating the impotent influence of this attribute to be substantial and is competent to expand the service quality performance presumed by the patient as a service organization that has an attribute in which the extent of quality service has not been enabled for developing patient's loyalty (Mahooti et al., 2018) (Ahmadzadeh Mashinchi, 2011; Kaihatu \& Djati, 2016; Mahooti et al., 2018). Thus, the study has hypothesized following relationship between organizational citizenship behavior and patient satisfaction.

H4:Organizational citizenship behavior has significant relationship with patient satisfaction.

\subsection{Moderating Role of Trustworthiness}

In addition, high social relevance has been exhibited with patient's satisfaction that energize their immune system and expand their motivation and discipline for observing to the treatment regimen in order to promote their recovery as number of studies in the medical area have revealed that there is a positive psychological influence of patient's satisfaction (Li, Yu, Liu, \& Huang, 2017) (Swain \& Kar, 2017) (Van Den Assem \& Dulewicz, 2015). In particular, one of the studies has examined the patient-doctor relationship from the perspective of a patient (Van Den Assem \& Dulewicz, 2014). The study has reported an explicit comparison between low and high-patient satisfaction clusters as well as their presumptions of the trustworthiness, performance, implications for practice, and practice orientation of doctors (Van Den Assem \& Dulewicz, 2014, 2015).

H5:Trustworthiness moderates the relationship between nursing service quality and patient satisfaction. H5:Trustworthiness moderates the relationship between hospital facilities quality and patient satisfaction. H5:Trustworthiness moderates the relationship between emotional exhaustion and patient satisfaction. H5:Trustworthiness moderates the relationship between organizational citizenship behavior and patient satisfaction.

\subsection{Conceptual Framework}

Based on the above theoretical discussion, the following model is conceptualized.

\section{Methodology}

Quantitative approach is used to study the relationship between hospital facilities, emotional exhaustion, OCB and patient satisfaction. In order to fulfill the objective, we targeted the patient of different hospitals. By using the Daniel Soper (2018) calculator, the sample was drawn. According to the calculation, 282 was the minimum sample requirement, therefore, we gathered 309 sample responses by using non-random convenience sampling.

\subsection{Measures}

The study has used five-point Likert scale questionnaire while the measures were adopted from various past published papers. In this regards, total three measures of nursing service quality and hospital facilities quality were adopted from Coutinho and da Costa Vieira (2018). In addition, nine measures of emotional exhaustion were adopted from MASLACH BURNOUT INVENTORY (MBI) scale, four measures of patient satisfaction were adopted from Coutinho and da Costa Vieira (2018). Additionally, organizational citizenship behavior (OCB) has two reflective first-order constructs i.e. altruism and general compliance 
proposed by Smith, Organ, and Near (1983). In this regards, six measures of altruism were adopted from Smith et al. (1983). However, trustworthiness was reflective higher-order comprising competence/ability, benevolence, integrity and risk aversion as suggested by Van Den Assem and Dulewicz (2014). Therein, four measures of competence/ability, benevolence, integrity and risk aversion were adopted from Van Den Assem and Dulewicz (2014).

\section{Data Analysis}

4.1 Respondent's Profile

Table I presents the results of demographic profile. Out of 292 respondent's, 202 were female and 90 were male. Majority of the respondents (i.e. 160) were fall in the age bracket 26-35, 91 respondents were in between 18-25, 29 were in between 36-45, and rest of the respondents (19) were above 45 age. Most of the people participated in the study were graduates (176) and post graduates (104). In the sample, 245 respondents were from private sector hospitals and only 47 respondents were from public sector hospitals.

\begin{tabular}{|c|c|c|c|c|c|}
\hline \multicolumn{6}{|c|}{ Demographic Profile $(n=292)$} \\
\hline \multicolumn{3}{|l|}{ Frequency } & \multicolumn{3}{|c|}{ Percent } \\
\hline Gender & \multicolumn{2}{|c|}{ Male } & \multirow[t]{2}{*}{90} & & 30.8 \\
\hline Female & & 202 & & \multicolumn{2}{|c|}{69.2} \\
\hline $\begin{array}{l}\text { Age Group (in } \\
\text { years) }\end{array}$ & \multicolumn{2}{|c|}{$18-25$} & \multicolumn{2}{|l|}{91} & 31.2 \\
\hline \multicolumn{2}{|l|}{$26-35$} & \multicolumn{2}{|l|}{160} & \multicolumn{2}{|l|}{54.8} \\
\hline \multicolumn{2}{|l|}{$36-45$} & \multicolumn{2}{|l|}{29} & \multicolumn{2}{|l|}{9.9} \\
\hline \multicolumn{2}{|l|}{ Above 45} & \multicolumn{2}{|l|}{12} & \multicolumn{2}{|l|}{4.1} \\
\hline $\begin{array}{l}\text { Academic } \\
\text { Qualification }\end{array}$ & \multicolumn{2}{|c|}{ Undergraduate } & \multicolumn{2}{|l|}{7} & 2.4 \\
\hline \multicolumn{2}{|l|}{ Graduate } & \multicolumn{2}{|l|}{176} & \multicolumn{2}{|l|}{60.3} \\
\hline \multirow{2}{*}{\multicolumn{2}{|c|}{ Post-Graduate }} & \multicolumn{2}{|l|}{104} & \multicolumn{2}{|l|}{35.6} \\
\hline & & \multicolumn{2}{|l|}{5} & \multicolumn{2}{|l|}{1.7} \\
\hline Marital Status & \multicolumn{2}{|c|}{ Single } & 148 & & 50.7 \\
\hline Married & & 144 & & \multicolumn{2}{|c|}{49.3} \\
\hline $\begin{array}{l}\text { Preferred } \\
\text { Hospital } \\
\text { Category }\end{array}$ & \multicolumn{2}{|c|}{$\begin{array}{l}\text { Private Sector } \\
\text { Hospital }\end{array}$} & \multicolumn{2}{|l|}{245} & 83.9 \\
\hline $\begin{array}{l}\text { Public } \\
\text { Hospital }\end{array}$ & ector & 47 & & 16.1 & \\
\hline
\end{tabular}

\subsection{Measurement Model}

Before testing the hypothesis, inner and outer measurement model have been assessed. Table 2 shows the results of construct validity and reliability. It is found from the findings that both the validity and reliability of the constructs are established. The values of outer loadings and average variance extracted show the construct validity and reliability. According to Hair et al., (2014), factor loadings should be greater than 0.6 and composite reliability value should be greater than 0.7. In addition, Sarstedt, Ringle, and Hair (2014) recommended that the value of AVE should be equal or greater than 0.50. As per the suggested criteria, all the values fall within the threshold. Therefore, we conclude that the construct validity and reliability of each construct is established. 
Table 2: Construct Validity \& Reliability

\begin{tabular}{|l|l|l|l|}
\hline $\begin{array}{l}\text { Construc } \\
\text { ts }\end{array}$ & Loadings & CR & AVE \\
\hline ALT1 & 0.641 & 0.876 & 0.589 \\
\hline ALT2 & 0.835 & \\
\hline ALT3 & 0.905 & \\
\hline ALT4 & 0.748 & \\
\hline ALT6 & 0.679 & \\
\hline Bene1 & 0.87 & 0.931 & 0.772 \\
\hline Bene2 & 0.859 & \\
\hline Bene3 & 0.852 & \\
\hline Bene4 & 0.932 & \\
\hline Comp1 & 0.92 & 0.943 & 0.807 \\
\hline Comp2 & 0.882 & \\
\hline Comp3 & 0.894 & \\
\hline Comp4 & 0.896 & \\
\hline EE1 & 0.798 & 0.894 & 0.586 \\
\hline EE2 & 0.733 & \\
\hline EE3 & 0.753 & \\
\hline EE7 & 0.757 & \\
\hline EE8 & 0.781 & \\
\hline EE9 & 0.767 & \\
\hline GC3 & 0.861 & 0.825 & 0.55 \\
\hline GC5 & 0.827 & \\
\hline GC6 & 0.732 & \\
\hline HFQ1 & 0.92 & 0.906 & 0.763 \\
\hline HFQ2 & 0.8 & \\
\hline HFQ3 & 0.897 & \\
\hline
\end{tabular}

Discriminant validity has substantial importance in the structural equation modeling and therefore, we assessed discriminant validity prior testing hypothesis. Following tables provide relevant information about the discriminant validity of the latent constructs. In PLS-SEM, there are majorly three types of discriminant validity including Fornell and Larcker (1981) criterion, cross loadings and HTMT ratio. According to the first criteria of Fornell \& Larcker (1981), the diagonal values which are the square root of AVE should be greater in their own construct. Table 3 reports the results of Fornell \& Larcker (1981), conclude that discriminant validity has been established among each construct because all the diagonal values are greater in its own construct. 
Table 3: Fornell and Larcker (1981) Criterion

\begin{tabular}{lcccccccccc}
\hline & ALT & BENE & COMP & EE & GC & HFQ & INTE & NSQ & PS & RA \\
\hline ALT & $\mathbf{0 . 7 6 8}$ & & & & & & & & & \\
BENE & 0.001 & $\mathbf{0 . 8 7 9}$ & & & & & & & & \\
COMP & 0.047 & 0.662 & $\mathbf{0 . 8 9 8}$ & & & & & & & \\
EE & 0.03 & -0.005 & -0.011 & $\mathbf{0 . 7 6 5}$ & & & & & \\
GC & 0.619 & -0.049 & -0.051 & -0.08 & $\mathbf{0 . 7 4 2}$ & & & & \\
HFQ & 0.003 & 0.217 & 0.197 & 0.074 & -0.035 & $\mathbf{0 . 8 7 4}$ & & & \\
INTE & -0.081 & 0.662 & 0.52 & -0.043 & -0.056 & 0.155 & $\mathbf{0 . 8 4}$ & & \\
NSQ & 0.04 & -0.066 & -0.172 & 0.029 & 0.046 & -0.489 & -0.119 & $\mathbf{0 . 7 6 9}$ & & \\
PS & 0.075 & 0.633 & 0.739 & -0.058 & 0.032 & 0.243 & 0.638 & -0.11 & $\mathbf{0 . 9 3}$ & \\
RA & -0.021 & 0.487 & 0.542 & -0.05 & 0.013 & 0.187 & 0.722 & -0.105 & 0.702 & $\mathbf{0 . 8 5}$ \\
\hline
\end{tabular}

Source: Author's estimation

The given table shows that all the HTMT ratio were found less than the recommended threshold of 0.85 (Henseler, Hubona, \& Ray, 2016; Henseler, Ringle, \& Sarstedt, 2015). Therefore, discriminant validity using HTMT ratio has been achieved.

\begin{tabular}{lcccccccccc}
\hline \multicolumn{1}{l}{ Table 4: Heterotrait-Monotrait (HTMT) Ratio } & & & & & \\
\hline \multicolumn{1}{l}{ ALT } & BENE & COMP & EE & GC & HFQ & INTE & NSQ & PS & RA \\
\hline ALT & & & & & & & & & & \\
BENE & 0.103 & & & & & & & & & \\
COMP & 0.117 & 0.72 & & & & & & & & \\
EE & 0.079 & 0.053 & 0.06 & & & & & & & \\
GC & 0.813 & 0.099 & 0.103 & 0.119 & & & & & \\
HFQ & 0.055 & 0.245 & 0.224 & 0.211 & 0.06 & & & & \\
INTE & 0.131 & 0.751 & 0.562 & 0.134 & 0.103 & 0.173 & & & \\
NSQ & 0.112 & 0.105 & 0.265 & 0.213 & 0.127 & 0.508 & 0.171 & & \\
PS & 0.107 & 0.679 & 0.784 & 0.063 & 0.056 & 0.262 & 0.705 & 0.119 & \\
RA & 0.074 & 0.538 & 0.596 & 0.071 & 0.088 & 0.217 & 0.843 & 0.142 & 0.768 \\
\hline
\end{tabular}

Source: Author's estimation

The following table 5 and table 6, reflective higher-order constructs of organizational citizenship behavior and trustworthiness. It is shown that reflective higher-order of organizational citizenship behavior has significantly reflected its first-order latent constructs of Altruism $(0.929, \mathrm{p}<0.001)$ and General Compliance $(0.866, \mathrm{p}<0.001)$.

\begin{tabular}{lccc}
\hline \multicolumn{4}{c}{ Table 5: Reflective construct of Organizational Citizenship Behavior } \\
\hline & Estimates & T-Stats & Prob. \\
\hline Altruism & 0.929 & 134.176 & 0.000 \\
General Compliance & 0.866 & 49.552 & 0.000 \\
\hline
\end{tabular}

Source: Author's estimation 
Another table showed that reflective higher-order of trustworthiness has significantly reflected its firstorder latent constructs of Benevolence $(0.850, \mathrm{p}<0.001)$, Competence/ability $(0.839, \mathrm{p}<0.001)$, Integrity $(0.840, \mathrm{p}<0.001)$ and Risk Aversion $(0.811, \mathrm{p}<0.001)$.

Table 6: Reflective Construct of Trustworthiness

\begin{tabular}{lccc}
\hline & Estimates & T-Stats & Prob. \\
\hline Benevolence & 0.85 & 53.574 & 0.000 \\
Competence/ability & 0.839 & 53.937 & 0.000 \\
Integrity & 0.84 & 64.359 & 0.000 \\
Risk Aversion & 0.811 & 39.843 & 0.000 \\
\hline
\end{tabular}

Source: Author's estimation

It has been manifested that path analysis is one of the sophisticated methods for hypothesis-testing (Nitzl \& Chin, 2017; Sarstedt, Henseler, \& Ringle, 2011) while path analysis has been substantially supported by Henseler and Fassott (2010) for moderating effect analysis. Therefore, following table 9 provides path analysis for hypothesis-testing using PLS bootstrapping technique executed at 5000 subsamples and 90 percent confidence interval.

\begin{tabular}{lcccc}
\hline Table 7: Hypothesis-Testing using Path Analysis & & & & \\
\hline & Estimates & S.D. & T-Stats & Prob. \\
\hline Emotional Exhaustion -> Patient Satisfaction & -0.038 & 0.055 & 0.694 & 0.487 \\
Hospital Facilities Quality -> Patient Satisfaction & 0.077 & 0.041 & 1.864 & 0.062 \\
Nursing Service Quality -> Patient Satisfaction & 0.046 & 0.054 & 0.866 & 0.387 \\
OCB -> Patient Satisfaction & 0.081 & 0.036 & 2.254 & 0.024 \\
Trustworthiness -> Patient Satisfaction & 0.803 & 0.029 & 27.922 & 0.000 \\
\hline
\end{tabular}

Above table showed that emotional exhaustion $(-0.038, \mathrm{p}>0.10)$ has been found as statistically insignificant while negatively affect patient satisfaction postulating that emotional exhaustion of the hospital staff somehow decrease patients' satisfaction. Moreover, hospital facilities quality $(0.077, \mathrm{p}<$ $0.10)$ and organizational citizenship behavior (OCB) of the hospital staff and employees $(0.081, p<0.05)$ have positively significant impact on patient satisfaction postulating that these aspects of the hospital in Karachi, Pakistan support to improve patient satisfaction and therefore, hospital facilities quality and organizational citizenship behavior add values to the overall hospital quality and patients' interaction and engagement. However, nursing service quality $(0.046, \mathrm{p}>0.10)$ has been found positive but statistically insignificant positing that there is no effect of nursing service quality on patient satisfaction in Karachi, Pakistan.

Table 8: Moderation Analysis

\begin{tabular}{lcccc}
\hline & Estimates & S.D. & T-Stats & Prob. \\
\hline TRUST x EE -> Patient Satisfaction & 0.033 & 0.039 & 0.858 & 0.391 \\
TRUST x HFQ -> Patient Satisfaction & -0.050 & 0.034 & 1.464 & 0.143 \\
TRUST x NSQ -> Patient Satisfaction & -0.032 & 0.035 & 0.926 & 0.354 \\
TRUST x OCB -> Patient Satisfaction & -0.010 & 0.032 & 0.295 & 0.768 \\
\hline
\end{tabular}


Trustworthiness (TRUST) does not moderates the relationship of emotional exhaustion $(0.033, \mathrm{p}>0.10)$, hospital facilities quality $(-0.050, \mathrm{p}>0.10)$, nursing service quality $(-0.032, \mathrm{p}>0.10)$ and organizational citizenship behavior $(-0.010, \mathrm{p}>0.10)$ with patient satisfaction. Following table 9 provides result of predictive relevance of the exogenous latent construct in the structural model including R-square, adjusted R-square and Q-square.

Table 9: Predictive Relevance

\begin{tabular}{lccc}
\hline & R Square & R Square Adjusted & Q Square \\
\hline Patient Satisfaction & 0.683 & 0.673 & 0.549 \\
\hline
\end{tabular}

It has been shown in the above table that 68.3 percent variability in patient satisfaction can be predicted by the combine effect of emotional exhaustion, hospital facilities quality, nursing service quality, organizational citizenship behavior and trustworthiness. However, Q-square was found as 54.9 percent that is higher than zero (Hair et al., 2011) and therein, predictive relevance using PLS-SEM has been achieved.

\section{Conclusion and Recommendations:}

The current paper revealed that emotional exhaustion of the hospital staff has a negative but statistically insignificant impact on patient satisfaction and it was found consistent with past studies (Dhaini et al., 2018; Pinchbeck et al., 2016). In this regards, Dhaini et al. (2018) stated that due to emotional exhaustion and burnout of the hospital employees, the consequences on patient will be adverse; but non-conforming behavior and job demand of the hospital staff, these consequences of emotional exhaustion and burnout may not cause any implications and imperatives on patient satisfaction (Bronwyn Hayes et al., 2014). Another study supported the similar argument positing that hospital staff are required to provide healthcare services (Pinchbeck et al., 2016); therefore, emotional exhaustion and other psychological deviance at the workplace may not act as barriers or hindering factors to their service provision The hypothesis of the study found consistent with past researches (Al-Hussami et al., 2017; Halim \& Sriwahyuni, 2017; Silva et al., 2018). Thesis studies have supported the perspective that hospital facilities quality significantly contributes to patient satisfaction (Halim \& Sriwahyuni, 2017; Santosh Kumar \& Bano, 2017). In this regards, Al-Hussami et al. (2017) manifested that patients found to be more comfortable and satisfied with the healthcare service quality if facilities were found satisfactory. In addition, hospital facilities quality play important role in improving patient satisfaction (Silva et al., 2018) while it has been found statistically significant in numerous past studies (Swain \& Kar, 2017; Ziapour et al., 2016).

Moreover, the results of the study have found that nursing service quality does not have any effect on patient satisfaction; however, these results were also found consistent with the previous researches (AlHussami et al., 2017; Aslan \& Yildirim, 2017; Edwards et al., 2018; Lukman et al., 2017b; Ríos-Risquez \& García-Izquierdo, 2016). In this connection, recent study showed that patient satisfaction does not directly affected by nursing service quality due to secondary consideration to these aspects (Aslan \& Yildirim, 2017). Furthermore, nurses are particularly involved and engaged for inpatient facilities (Lukman et al., 2017b), whereas outpatient facilities at healthcare organizations and hospitals were not prominent; therein, nursing service quality may not affect patient satisfaction (Ríos-Risquez \& GarcíaIzquierdo, 2016). However, another study presented the viewpoint that nursing service quality was found important for inpatient services in hospital postulating the perspective that nursing services were considered important for inpatients rather than outpatients prominently (Al-Hussami et al., 2017; Edwards et al., 2018). 
In further, the study has found that organizational citizenship behavior has significantly positive impact on patient satisfaction and therein, numerous past researches have supported the similar viewpoint in recent times (Ahmadzadeh Mashinchi, 2011; Kaihatu \& Djati, 2016; Mahooti et al., 2018)

The studies have shown that organizational citizenship behavior leads to higher propensity of providing services in out-of-the-way context and delivering services in the best of their practice (Ahmadzadeh Mashinchi, 2011). Some authors have suggested that OCB can be an initiating aspect of providing exclusive services in context to hospital due to high patient interaction and sympathetic aspects of the hospital and medical staff (Kaihatu \& Djati, 2016). There were researches positing that work meaningfulness leads to higher tendency of vigor and ultimately providing their work-related services to the next level and contributes largely (Mahooti et al., 2018). In addition, organizational citizenship behavior have two major determinants i.e. work meaningfulness and positive well-being and therefore, these aspects contribute to their gratitude and kindness at the workplace with coworkers, partners and customers (Lu, Zhao, \& While, 2019); hence, these studies also supported the results and findings of the current study.

Lastly, the results have found that trustworthiness does not moderate the relationship of emotional exhaustion, hospital facilities quality, nursing service quality and organizational citizenship behavior with patient satisfaction. However, these results have been supported by numerous past studies but the circumstances were obviously interesting (Connelly, 2016; Moolasarn, 2017; Swain \& Kar, 2017). In an empirical study, it has been provided that due to lack of consistency in the healthcare service provision, trustworthiness may not constitute any importance (Moolasarn, 2017); whereby, Connelly (2016) manifested that trustworthiness may not accompanied in the healthcare industry due to its time-being need and perception (Swain \& Kar, 2017). It has been exhibited that trustworthiness may have some imperatives for inpatient services but have lack of significance in outpatient service provision. These results have particularly supported the viewpoint that trustworthiness does not have any implications for outpatient hospital services and therein, consistent with the result and finding of the current study. The facilities designed at hospitals are more focused on reduction of patient retention time, which is the obvious requirement for the customer bases of hospitals. Issues may arise if the periodic patient observations are not followed as per schedule. Hospital management should be focused on developing and maintaining checks and balances for patient monitoring staff alongside their task associated equipment, disposable apparatus, medicine etc. for rejuvenation.

\section{References}

Ab Hamid, M.R., Mustafa, Z., Suradi, N.R.M., Abdullah, M., Idris, F., Ismail, W.R., . . Abidin,

N.Z. (2010). Measuring leadership values based on value-based total performance excellence model (vbtpem). Bus. Manage. Q. Rev., 1(3), 64-79.

Ahmadzadeh Mashinchi, S. (2011). An analysis of correlation between organizational citizenship behavior (ocb) and emotional intelligence (ei).

Al-Hussami, M., Al-Momani, M., Hammad, S., Maharmeh, M., \& Darawad, M. (2017). Patients' perception of the quality of nursing care and related hospital services. Health and Primary Care, 1(2), 1-6. Aljaberi, M.A., Juni, M.H., Al-Maqtari, R.A., Lye, M.S., Saeed, M.A., Al-Dubai, S.A.R., \& Shahar, H.K. (2018). Relationships among perceived quality of healthcare services, satisfaction and behavioural intentions of international students in kuala lumpur, malaysia: A cross-sectional study. BMJ open, 8(9), e021180.

Asika, N. (1991). Research methodology in the behavioural sciences. Lagos: Longman Nigeria Plc, 90-96.

Aslan, M., \& Yildirim, A. (2017). Personality and job satisfaction among nurses: The mediating effect of contextual performance. International Journal of Caring Sciences, 10(1).

Bhattacherjee, A. (2012). Social science research: Principles, methods, and practices (2nd ed.). California, USA: CreateSpace Independent Publishing Platform.

Bhattacherjee, A., \& Premkumar, G. (2004). Understanding changes in belief and attitude toward information technology usage: A theoretical model and longitudinal test. MIS quarterly, 229-254. 
Bhattacherjee, A., \& Premkumar, G. (2008). Explaining information technology usage: A test of competing models. Omega, 36(1), 64-75.

Brink, H., Van der Walt, C., \& Van Rensburg, G. (2006). Fundamentals of research methodology for health care professionals: Juta and Company Ltd.

Connelly, L.M. (2016). Trustworthiness in qualitative research. Medsurg Nursing, 25(6), 435-437.

Coutinho, E.D., \& da Costa Vieira, P.R. (2018). Antecedents of oncological patient satisfaction: A study conducted at the brazilian national cancer institute. International Review on Public and Nonprofit Marketing, 15(3), 413-429.

Creswell, J.W. (2009). Research design: Qualitative, quantitative, and mixed methods approaches. USA: Sage publications.

Demirkiran, M., Taskaya, S., \& Dinc, M. (2016). A study on the relationship between organizational justice and organizational citizenship behavior in hospitals. Int. J. Bus. Manage. Econ. Res, 7, 547-554.

Dhaini, S.R., Denhaerynck, K., Bachnick, S., Schwendimann, R., Schubert, M., De Geest, S., . . group, M.R.s. (2018). Work schedule flexibility is associated with emotional exhaustion among registered nurses in swiss hospitals: A cross-sectional study. International journal of nursing studies, 82, 99-105.

Dillman, D.A. (2011). Mail and internet surveys: The tailored design method--2007 update with new internet, visual, and mixed-mode guide: John Wiley \& Sons.

Dooley, D., \& Gullickson, T. (1995). Social research methods. Psyccritiques, 40(10), 1016.

Edwards, S.T., Helfrich, C.D., Grembowski, D., Hulen, E., Clinton, W.L., Wood, G.B., . . . Stewart, G. (2018). Task delegation and burnout trade-offs among primary care providers and nurses in veterans affairs patient aligned care teams (va pacts). The Journal of the American Board of Family Medicine, 31(1), 83-93.

Fornell, C., \& Larcker, D.F. (1981). Structural equation models with unobservable variables and measurement error: Algebra and statistics. Journal of marketing research, 18(3), 382-388.

Haenlein, M., \& Kaplan, A.M. (2004). A beginner's guide to partial least squares analysis. Understanding statistics, 3(4), 283-297.

Hair, J.F., Hollingsworth, C.L., Randolph, A.B., \& Chong, A.Y.L. (2017). An updated and expanded assessment of pls-sem in information systems research. Industrial Management \& Data Systems, 117(3), 442-458.

Hair, J.F., Hult, G.T.M., Ringle, C., \& Sarstedt, M. (2016). A primer on partial least squares structural equation modeling (pls-sem): Sage Publications.

Hair, J.F., Ringle, C.M., \& Sarstedt, M. (2011). Pls-sem: Indeed a silver bullet. Journal of Marketing theory and Practice, 19(2), 139-152.

Hair, J.F., Sarstedt, M., Hopkins, L., \& Kuppelwieser, V.G. (2014). Partial least squares structural equation modeling (pls-sem) an emerging tool in business research. European Business Review, 26(2), 106-121.

Halim, P., \& Sriwahyuni, I. (2017). Patient satisfaction level at local general hospital in mamuju regency, indonesia. International Journal of Science and Research (IJSR), 6(9), 1-5.

Halstead, D., Hartman, D., \& Schmidt, S.L. (1994). Multisource effects on the satisfaction formation process. Journal of the Academy of marketing science, 22(2), 114-129.

Harmon-Jones, E., \& Harmon-Jones, C. (2007). Cognitive dissonance theory after 50 years of development. Zeitschrift für Sozialpsychologie, 38(1), 7-16.

Hayes, B., Douglas, C., \& Bonner, A. (2014). Predicting emotional exhaustion among haemodialysis nurses: A structural equation model using kanter's structural empowerment theory. Journal of advanced nursing, 70(12), 2897-2909.

Hayes, B., Douglas, C., \& Bonner, A. (2015). Predicting emotional exhaustion among haemodialysis nurses: A structural equation model using kanter's structural empowerment theory. JOB SATISFACTION, STRESS AND BURNOUT IN HAEMODIALYSIS NURSES, 190.

Henseler, J., \& Fassott, G. (2010). Testing moderating effects in pls path models: An illustration of available procedures Handbook of partial least squares (pp. 713-735): Springer.

Henseler, J., Hubona, G., \& Ray, P.A. (2016). Using pls path modeling in new technology research: Updated 
guidelines. Industrial management \& data systems, 116(1), 2-20.

Henseler, J., Ringle, C.M., \& Sarstedt, M. (2015). A new criterion for assessing discriminant validity in variancebased structural equation modeling. Journal of the academy of marketing science, 43(1), 115-135.

Janssen, O., Lam, C.K., \& Huang, X. (2010). Emotional exhaustion and job performance: The moderating roles of distributive justice and positive affect. Journal of Organizational Behavior, 31(6), 787-809.

Kothari, C.R. (2004). Research methodology: Methods and techniques: New Age International.

Koul, L. (2009). Methodology of educational research: Vikas publishing house PVT Ltd.

Kumar, S., \& Bano, S. (2017). Comparison and analysis of health care delivery systems: Pakistan versus bangladesh. Journal of Hospital and Medical Management, 3(1), 1-7.

Kumar, S., \& Phrommathed, P. (2005). Research methodology: Springer.

Liberatore, F., Angerer, A., \& Kriech, S. (2017). The balance of patient and learners needs in non-profit, public and for-profit teaching hospitals: An analysis of average patient satisfaction ratings of hospitals on a german hospital rating platform. International Journal of Healthcare Management, 1-7.

Lu, H., Zhao, Y., \& While, A. (2019). Job satisfaction among hospital nurses: A literature review. International journal of nursing studies.

Lukman, H., Tiara, P.R., \& Mei, W. (2017a). The quality of patient satisfaction with service inside of health care of a systematic review.

Mahooti, M., Vasli, P., \& Asadi, E. (2018). Effect of organizational citizenship behavior on family-centered care: Mediating role of multiple commitment. PloS one, 13(9), e0204747.

Maslach, C., \& Jackson, S.E. (1981). The measurement of experienced burnout. Journal of Occupational Behavior, 2(1), 99-113.

Nelson, K.M., Helfrich, C., Sun, H., Hebert, P.L., Liu, C.-F., Dolan, E., . . . Hernandez, S.E. (2014). Implementation of the patient-centered medical home in the veterans health administration: Associations with patient satisfaction, quality of care, staff burnout, and hospital and emergency department use. JAMA internal medicine, 174(8), 1350-1358.

Neuman, W.L. (2013). Social research methods: Qualitative and quantitative approaches: Pearson education.

Nitzl, C., \& Chin, W.W. (2017). The case of partial least squares (pls) path modeling in managerial accounting research. Journal of Management Control, 28(2), 137-156.

Noor, K.B.M. (2008). Case study: A strategic research methodology. American journal of applied sciences, 5(11), $1602-1604$.

Nunnally, J.C. (1978). Psychometric methods. New York: McGraw-Hill.

Nunnally, J.C., \& Bernstein, I.H. (1994). Psychometric theory (Vol. 3). New York: McGraw-Hill.

Oliver, R.L. (1980). A cognitive model of the antecedents and consequences of satisfaction decisions. Journal of marketing research, 460-469.

Pinchbeck, C., Weygandt, P., Gisondi, M., \& Lu, D. (2016). Emergency medicine trainees with high emotional exhaustion are associated with lower patient satisfaction scores. Western Journal of Emergency Medicine: Integrating Emergency Care with Population Health, 17(4.1).

Rafidah, A., Nurulhuda, A., \& Suhaila, Y. (2017). A comparative study of service quality on patient satisfaction between public hospital in johor bahru, malaysia. The Social Sciences, 12(3), 524-529.

Reinartz, W., Haenlein, M., \& Henseler, J. (2009). An empirical comparison of the efficacy of covariance-based and variance-based sem. International Journal of research in Marketing, 26(4), 332-344.

Ricci-Cabello, I., Stevens, S., Dalton, A.R., Griffiths, R.I., Campbell, J.L., \& Valderas, J.M. (2018). Identifying primary care pathways from quality of care to outcomes and satisfaction using structural equation modeling. Health services research, 53(1), 430-449.

Ríos-Risquez, M.I., \& García-Izquierdo, M. (2016). Patient satisfaction, stress and burnout in nursing personnel in emergency departments: A cross-sectional study. International journal of nursing studies, 59, 60-67.

Sahu, E.H., Abdullah, M.U., \& Masood, R.T. (2017). Patient satisfaction from dental services provided by multan medical \& dental college. Annals, 2(1), 26-30.

Santos, J., \& Boote, J. (2003). A theoretical exploration and model of consumer expectations, post-purchase 
affective states and affective behaviour. Journal of Consumer Behaviour: An International Research Review, 3(2), 142-156.

Sarstedt, M., Henseler, J., \& Ringle, C.M. (2011). Multigroup analysis in partial least squares (pls) path modeling: Alternative methods and empirical results Measurement and research methods in international marketing (pp. 195-218): Emerald Group Publishing Limited.

Sarstedt, M., Ringle, C.M., \& Hair, J.F. (2014). Pls-sem: Looking back and moving forward: Elsevier.

Shah, P.D., Calo, W.A., Marciniak, M.W., Golin, C.E., Sleath, B.L., \& Brewer, N.T. (2018). Service quality and parents' willingness to get adolescents hpv vaccine from pharmacists. Preventive medicine, 109, 106-112.

Shanafelt, T.D., Hasan, O., Dyrbye, L.N., Sinsky, C., Satele, D., Sloan, J., \& West, C.P. (2015). Changes in burnout and satisfaction with work-life balance in physicians and the general us working population between 2011 and 2014. Paper presented at the Mayo Clinic Proceedings.

Silva, A.G.G., Ferreira, P.L., \& Daniel, F.B. (2018). Portuguese university hospital patient satisfaction and service quality. International journal of health care quality assurance(just-accepted), 00-00.

Tartaglione, A.M., Cavacece, Y., Cassia, F., \& Russo, G. (2018). The excellence of patient-centered healthcare: Investigating the links between empowerment, co-creation and satisfaction. The TQM Journal, 30(2), 153167.

Van Den Assem, B., \& Dulewicz, V. (2014). Patient satisfaction and gp trustworthiness, practice orientation and performance: Implications for selection, training and revalidation. Journal of health organization and management, 28(4), 532-547.

Van Den Assem, B., \& Dulewicz, V. (2015). Doctors' trustworthiness, practice orientation, performance and patient satisfaction. International journal of health care quality assurance, 28(1), 82-95.

Ziapour, A., Khatony, A., Jafari, F., \& Kianipour, N. (2016). Patient satisfaction with medical services provided by a hospital in kermanshah-iran. Acta Med Mediterranea, 32, 959-965. 
